\title{
Improvement in Endothelial Function by Angiotensin Converting Enzyme Inhibition in Insulin-dependent Diabetes Mellitus
}

\author{
Gerard O’Driscoll, ${ }^{\star}$ Daniel Green, ${ }^{\S}$ Jamie Rankin, ${ }^{\star}$ Kim Stanton, ${ }^{\ddagger}$ and Roger Taylor \\ $*$ Department of Cardiology and Medicine, and ${ }^{\ddagger}$ Department of Endocrinology and Diabetes, Royal Perth Hospital, Australia; and \\ ${ }^{\S}$ Department of Human Movement, The University of Western Australia, Australia
}

\begin{abstract}
We postulated that nitric oxide (NO)-mediated endothelial function would be improved by acute and short-term treatment with an angiotensin converting enzyme (ACE) inhibitor in patients with type I diabetes mellitus, in whom endothelial function is depressed. Nine type I diabetic patients and eight healthy subjects underwent forearm blood flow measurement using strain gauge plethysmography during intraarterial infusion of incremental doses of endotheliumdependent (acetylcholine [ACh]) and endothelium-independent (sodium nitroprusside [SNP]) vasodilators. Pretreatment $\mathrm{ACh}$ responses were depressed in diabetic patients relative to the normal subjects $(P<0.05)$. No difference between the groups was evident in response to SNP. Acute ACE inhibition (with intrabrachial enalaprilat) enhanced ACh responses in the diabetic patients $(P<0.005)$, with a further improvement evident after 1 mo of oral therapy with enalapril $(P<0.001)$ when $\mathrm{ACh}$ responses were normalized. ACE inhibition did not affect SNP responses. We conclude that acute administration of the ACE inhibitor, enalaprilat, enhances NO-mediated endothelial function in type I diabetic patients, with further improvement evident after 4 wk of enalapril therapy. (J. Clin. Invest. 1997. 100: 678-684.) Key words: endothelium • insulin-dependent diabetes mellitus - angiotensin converting enzyme inhibition • plethysmography $\bullet$ nitric oxide
\end{abstract}

\section{Introduction}

In recent years the important contribution of endothelial cell function to control of the arterial circulation has been recognized. Furthermore, endothelium-derived mediators, in particular nitric oxide (NO), ${ }^{1}$ not only regulate vascular smooth muscle tone and proliferation but influence the adhesion and interaction of platelets and monocytes with the vessel wall. Impaired endothelium-dependent dilatation has been reported in

Address correspondence to Dr. Gerald O'Driscoll, Department of Cardiology, Royal Perth Hospital, Wellington Street, Perth 6000, Western Australia. Phone: 618-9224-1462; FAX: 618-9224-3175; E-mail: gerrodri@dunamis.rph.uwa.edu.au

Received for publication 21 January 1997 and accepted in revised form 23 April 1997.

1. Abbreviations used in this paper: $\mathrm{ACE}$, angiotensin converting enzyme; ACh, acetylcholine; FBF, forearm blood flow; NO, nitric oxide; SNP, sodium nitroprusside.

J. Clin. Invest.

(C) The American Society for Clinical Investigation, Inc. 0021-9738/97/08/0678/07 \$2.00

Volume 100, Number 3, August 1997, 678-684

http://www.jci.org subjects with various risk factors for vascular disease such as hypercholesterolemia (1), hypertension (2), and cigarette smoking $(3,4)$, either with or without obvious atheromatous disease (5), so that endothelial dysfunction may be regarded as a manifestation of the genesis of the atherosclerotic process (6).

Insulin-dependent (type I) diabetes is associated with increased mortality and morbidity mainly due to the complications of vascular disease. In animal models of diabetes, there is good evidence of endothelial dysfunction $(7,8)$ including impaired responsiveness to vasodilators having an endotheliumdependent effect, such as acetylcholine (ACh), and normal responsiveness to those, such as sodium nitroprusside (SNP), with an endothelium-independent effect. The few studies performed in patients with type I diabetes have produced equivocal results, some indicating that endothelium-dependent vasodilation stimulated by muscarinic agonists is similar to that in healthy control subjects $(9,10)$, others reporting abnormal responses to these agonists (11) or depressed basal NO-mediated vasodilator tone $(9,10)$.

Administration of angiotensin converting enzyme (ACE) inhibitors has been reported to reverse impaired endotheliumdependent responses to ACh in patients with heart failure (12, 13) and hypertension (14), and probably to improve endothelial function even in normal subjects (15). In addition, a recent study demonstrated improvement in coronary endothelial function after 6 mo of treatment with an ACE inhibitor in patients with coronary obstructive disease (16). However, the forearm blood flow (FBF) response to the endothelium-dependent vasodilator, methacholine, was reported to be unimproved by 6 mo of ACE inhibitor therapy in type II diabetics (17) despite firm evidence that ACE inhibition slows the progressive development of albuminuria and renal failure, at least in type I diabetic patients $(18,19)$. Since ACE inhibitor drugs are now widely used in such patients, their effect on endothelial function is likely to be of great importance. This study was therefore designed primarily to determine whether the acute administration or short-term treatment with an ACE inhibitor enhances endothelial function in insulin-dependent diabetic patients.

\section{Methods}

Subjects. Nine male subjects ( $43 \pm 3 \mathrm{yr})$ with type I diabetes mellitus (duration $18 \pm 2 \mathrm{yr}$ ) without evidence of microvascular or macrovascular complications were recruited. They underwent a screening program consisting of medical history and examination, hematological and biochemical profile, including measurement of blood glucose, serum electrolytes, urea and creatinine, uric acid, liver function, and serum lipids. The following subjects were excluded: those with renal impairment or proteinuria, hepatic impairment, gout or hyperuricemia, hypercholesterolemia (total cholesterol $>5.5 \mathrm{mmol} /$ liter), or hypertension ( $>140 / 90 \mathrm{mmHg}$ ); those taking vitamin supplements, ACE inhibitors, or any medication other than insulin. All subjects had normal electrocardiograms and chest $\mathrm{x}$ rays. None had microalbuminuria on quantitative assessment (24-h excretion using nephelometric method). Full-field photography was performed to assess retinopa- 
thy; two subjects had mild background retinopathy and one had undergone laser treatment in the past. One subject had evidence of a mild sensory neuropathy; all others had normal neurological examination. The mean glycosylated hemoglobin at entry was $8.3 \pm 0.4 \%$ (normal range $=4.3-6.0 \%$ ). The study protocol was approved by Royal Perth Hospital Ethics Committee and subjects gave written informed consent.

Study design. In addition to studying the effects of ACE inhibition in the diabetic patients, their pretreatment results were compared with those of eight healthy male volunteers $(28 \pm 2 \mathrm{yr})$ previously studied (20) and who had attended the laboratory on one occasion when forearm vascular responses to intrabrachial ACh and SNP infusion were determined. This was also undertaken during the initial session attended by the diabetic patients. In these patients the effect of acute ACE inhibition was also determined during the initial session by coinfusion of ACh and SNP with enalaprilat. The effect of short-term ACE inhibition was examined in a second laboratory session after $4 \mathrm{wk}$ of oral enalapril therapy. Patients continued their usual insulin regimen and biochemical and hematological parameters were repeated at each visit. All volunteers refrained from drinking alcohol or caffeine-containing beverages for $12 \mathrm{~h}$ before the laboratory sessions. There were no adverse side effects.

Protocol. Investigations were conducted in a quiet, climate controlled laboratory $\left(24^{\circ} \mathrm{C}\right.$, relative humidity $\left.55 \%\right), \sim 3 \mathrm{~h}$ after the usual insulin dose had been administered, with subjects lying supine and both forearms supported above heart level. A 20 gauge arterial cannula (Arrow International, Reading, PA) was introduced into the brachial artery of the nondominant arm under local anesthesia with $<2 \mathrm{ml}$ of $1 \%$ lidocaine (Astra Pharmaceuticals, Sydney, Australia) to transduce pressure, for the infusion of drugs or physiological saline, and for intermittent sampling of arterial blood. A second cannula was inserted into a forearm vein for insulin and dextrose infusions. FBF $(\mathrm{ml} / 100 \mathrm{ml}$ forearm/min) was measured simultaneously in both arms by gallium/indium strain gauge (SG24; Medasonics, Mountain View, CA) plethysmography. Wrist cuffs, connected to a flow-regulated source of compressed air, and arm cuffs, connected to a rapid inflation device (E20; Hokanson, Bellevue, WA), were placed on each limb. Output from the strain gauges passed through an amplifier (SPG 16; Medasonics) and was sampled by an on-line microcomputer at $75 \mathrm{~Hz}$ before being displayed on a monitor in real time. A software program coordinated the acquisition, storage, and display of data as well as inflation and deflation of the arm cuffs, ensuring that blood flow measures were synchronized with cuff inflation during recording periods. Intraarterial pressure was measured continuously (Transpac; Abbot Laboratories, Chicago, IL) throughout the study. Drug infusions were administered using a constant-rate infusion pump (IVAC 770; IVAC Corp., CA).

Baseline measurements started at least 25 min after cannulation of the brachial artery, when FBF and blood glucose had stabilized. Blood flow measurements were taken by inflating the wrist cuffs to $220 \mathrm{mmHg}$, to exclude the hands from the circulation, and by rapidly inflating the upper arm cuffs to $45 \mathrm{mmHg}$ for 10 out of every $15 \mathrm{~s}$ throughout the baseline and drug infusion periods. Output from the strain gauges was stored and the average of the last five flow measurements from each period was used for analysis. Between infusions, the cuffs were deflated, allowing at least $15 \mathrm{~min}$ for FBF to recover from the preceding infusion before further baseline measures were recorded.

All solutions were prepared aseptically from sterile stock solutions or ampoules immediately before infusion into the brachial artery. ACh (Miochol; Johnson \& Johnson, Sydney, Australia) was infused at 10,20 , and $40 \mu \mathrm{g} / \mathrm{min}$, each for $3 \mathrm{~min}$, to produce a cumulative dose-response curve. After a 20-min recovery period, SNP (David Bull Laboratories, Melbourne, Australia) was infused at 2,4 , and $8 \mu \mathrm{g} / \mathrm{min}$, each for $3 \mathrm{~min}$. This was followed, in the diabetic patients, by continuous intraarterial infusion of enalaprilat (Merck Sharpe \& Dohme, Sydney, Australia) at $8.3 \mu \mathrm{g} / \mathrm{min}$. After further baseline measurements, the ACh and SNP infusions were repeated during coinfusion with enalaprilat.
After the initial session, the diabetic patients received enalapril (Renitec; Merck Sharpe \& Dohme) $10 \mathrm{mg}$ twice daily for $4 \mathrm{wk}$ and returned for a repeat study during which the responses to $\mathrm{ACh}$ and SNP were again measured. The repeat study was performed, on average, $4 \mathrm{~h}$ after ingestion of enalapril.

Throughout each study session, insulin was delivered by a continuous, constant-rate intravenous infusion (set at either 1 or $2 \mathrm{U} / \mathrm{h}$ depending on the blood glucose on arrival at the laboratory), and blood glucose was maintained between 5 and $12 \mathrm{mmol} /$ liter by determining blood glucose concentrations every $5 \mathrm{~min}$ and periodically adjusting a variable rate $25 \%$ dextrose infusion. Serum potassium was measured serially in three subjects but since there was no change it was not measured in the other studies.

Analysis. Although the low doses of drugs infused in the study produced negligible systemic effects and showed no effect on blood pressure or heart rate, it is still desirable to exclude an alteration in overall hemodynamics as a cause of the flow changes seen in the infused forearm. These considerations, and the mode of expression of FBF to which they lead, have been reviewed recently (21). Thus, FBF was measured simultaneously in both arms, although only one arm was infused, and the noninfused arm served as a control. As in other studies $(2,22)$, FBF in the infused arm is described as a ratio to that in the noninfused arm. Changes in these ratios during ACh and SNP infusions are expressed as percent changes from the baseline immediately preceding each drug administration. In addition, vascular resistance was calculated in the infused arm as the ratio of mean arterial pressure to $\mathrm{FBF}$ and expressed in units of $\mathrm{mmHg}$ per $\mathrm{ml} / 100 \mathrm{ml}$ tissue/minute.

Results are expressed as means \pm SE. The responses after acute and after short-term ACE inhibition were compared to pretreatment responses, and the latter to responses in the normal subjects, using two-way ANOVA with repeated measures performed on the three dose levels of ACh and SNP. $P<0.05$ was considered significant.

\section{Results}

Characteristics of the diabetic patients and normal subjects are presented in Table I, along with the baseline serum lipid and blood glucose, heart rate, and blood pressure data collected at each session. Mean arterial pressure did not change during the acute study with enalaprilat infusion but was significantly lower after 4 wk of enalapril therapy $(P<0.001)$. Heart rate

Table I. Subject Characteristics

\begin{tabular}{|c|c|c|c|c|}
\hline & \multicolumn{3}{|c|}{ Diabetic patients } & \multirow[b]{2}{*}{ Normal subject } \\
\hline & Pretreatment & Enalaprilat & $4 \mathrm{wk}$ enalapril & \\
\hline $\begin{array}{l}\text { Blood glucose } \\
(\mathrm{mmol} / \text { liter })\end{array}$ & $8.1 \pm 1.1$ & $6.9 \pm 0.7$ & $9.1 \pm 0.9$ & \\
\hline \multicolumn{5}{|c|}{ Cholesterol (mmol/liter) } \\
\hline Total & $4.5 \pm 0.3$ & & $4.4 \pm 0.4$ & $4.6 \pm 0.3$ \\
\hline LDL & $2.9 \pm 0.2$ & & $3.3 \pm 0.4$ & $2.6 \pm 0.2$ \\
\hline HDL & $1.3 \pm 0.1$ & & $1.3 \pm 0.1$ & $1.4 \pm 0.2$ \\
\hline $\begin{array}{l}\text { Triglycerides } \\
\qquad(\mathrm{mmol} / \text { liter })\end{array}$ & $0.9 \pm 0.1$ & & $0.9 \pm 0.1$ & $1.4 \pm 0.2$ \\
\hline $\begin{array}{l}\text { Mean arterial } \\
\text { pressure }(\mathrm{mmHg})\end{array}$ & $93 \pm 1$ & $92 \pm 1$ & $86 \pm 1 *$ & $86 \pm 2$ \\
\hline Heart rate (bpm) & $62 \pm 1$ & $60 \pm 1^{\ddagger}$ & $62 \pm 1$ & $58 \pm 2$ \\
\hline
\end{tabular}

Values are means \pm SE. Significance of differences from pretreatment values: $* P<0.001,{ }^{\ddagger} P<0.01$. 
Table II. FBF in the Infused and Noninfused Limbs at Baseline and During ACh Infusion for Each Study Session

\begin{tabular}{|c|c|c|c|c|c|c|}
\hline & & & \multicolumn{3}{|c|}{ Diabetic patients } & \multirow[b]{2}{*}{ Normal subjects } \\
\hline & & & Pretreatment & Enalaprilat & 4 wk enalapril & \\
\hline \multirow{4}{*}{ Infused arm } & Baseline & & $2.2 \pm 0.2$ & $2.2 \pm 0.3$ & $2.5 \pm 0.3$ & $3.0 \pm 0.6$ \\
\hline & $\mathrm{ACh}$ & $10 \mu \mathrm{g} / \mathrm{min}$ & $3.2 \pm 0.4$ & $4.3 \pm 0.6$ & $5.1 \pm 0.6$ & $5.7 \pm 1.0$ \\
\hline & & $20 \mu \mathrm{g} / \mathrm{min}$ & $4.3 \pm 0.5$ & $5.1 \pm 0.7$ & $6.9 \pm 0.6$ & $8.3 \pm 2.1$ \\
\hline & & $40 \mu \mathrm{g} / \mathrm{min}$ & $5.2 \pm 0.6$ & $5.9 \pm 0.9$ & $9.3 \pm 1.2$ & $11.5 \pm 2.7$ \\
\hline \multirow[t]{4}{*}{ Noninfused arm } & Baseline & & $3.1 \pm 0.5$ & $2.6 \pm 0.4$ & $2.9 \pm 0.3$ & $4.4 \pm 1.0$ \\
\hline & $\mathrm{ACh}$ & $10 \mu \mathrm{g} / \mathrm{min}$ & $3.1 \pm 0.5$ & $2.3 \pm 0.3$ & $2.6 \pm 0.3$ & $4.8 \pm 1.1$ \\
\hline & & $20 \mu \mathrm{g} / \mathrm{min}$ & $3.1 \pm 0.4$ & $2.4 \pm 0.3$ & $2.7 \pm 0.2$ & $5.2 \pm 1.2$ \\
\hline & & $40 \mu \mathrm{g} / \mathrm{min}$ & $3.2 \pm 0.5$ & $2.2 \pm 0.3$ & $2.7 \pm 0.3$ & $4.8 \pm 1.1$ \\
\hline
\end{tabular}

Values are means $\pm \mathrm{SE}(\mathrm{ml} / 100 \mathrm{ml}$ forearm/min). ANOVA with repeated measures indicated a significant difference between pretreatment diabetic patients and normal subjects in the infused arm $(P<0.005)$. The response to ACh after $4 \mathrm{wk}$ of enalapril improved relative to both the pretreatment responses $(P<0.001)$ and to those during enalaprilat $(P=0.05)$ in the infused arm.

decreased slightly during enalaprilat infusion $(P<0.01)$ but was not significantly different from the baseline study after 4 wk of enalapril therapy.

Absolute FBF data recorded in the infused and noninfused limbs at baseline and during the infusion of ACh at three dose levels in the control state, after enalaprilat administration, and after $4 \mathrm{wk}$ of treatment with enalapril are presented in Table II. The absolute flow data related to SNP infusion are presented in Table III. An adequate wash-out period between infusion of each of the three drugs, ACh, SNP, and enalaprilat, is evidenced by the fact that the baseline FBF values preceding each drug were not different (Tables II and III).

Pretreatment responses of diabetic patients to ACh were significantly depressed relative to those of the normal subjects $(P<0.005$, Table II). Table II indicates that neither the acute administration of enalaprilat nor $4 \mathrm{wk}$ of administration of enalapril to diabetic subjects significantly influenced basal FBF. During infusion of enalaprilat in the diabetic patients, the responses of absolute FBF to ACh tended to be augmented, although not significantly. 4 wk of enalapril therapy significantly increased the responses to ACh (Table II). For example, mean FBF in the infused arm increased from a baseline value of $2.2 \mathrm{ml} / 100 \mathrm{ml}$ per min to $5.2 \mathrm{ml} / 100 \mathrm{ml}$ per min, an increase of $136 \%$, in response to the highest dose of $\mathrm{ACh}$ in the pretreatment period. After 4 wk of enalapril therapy, a baseline value of $2.5 \mathrm{ml} / 100 \mathrm{ml}$ per min was increased to 9.3 $\mathrm{ml} / 100 \mathrm{ml}$ per min, a $277 \%$ increase, by ACh. ANOVA indicated that the responses to ACh, in terms of absolute FBF, improved relative to both the pretreatment responses $(P<$ $0.001)$ and to those during enalaprilat $(P=0.05$, Table II) and were not significantly different to the responses of the normal subjects $(P=0.43)$. In contrast, the responses to SNP were unchanged by both enalaprilat infusion and enalapril therapy.

As described in Methods, it is of some importance to analyze the data in terms of FBF ratios, that is, the ratio of flow in the infused arm to that in the noninfused arm, and to refer these to the baseline measurements. Table IV presents the percent changes in these ratios in response to ACh and SNP for the diabetic patients pretreatment, during infusion of enalaprilat, and after 4 wk of enalapril therapy, while Fig. 1 illustrates these responses. The improvement in the responses to ACh, produced by enalaprilat, was significant $(P<0.005$, Table IV, Fig. 1), while the effect of enalapril on the responses to ACh was significant when compared both to pretreatment $(P<0.001)$ and enalaprilat $(P<0.05)$ data. Analysis of the data in terms of forearm vascular resistance revealed similar findings, that is, effects of both enalaprilat and enalapril at the same significant levels (Table V).

Table III. FBF in the Infused and Noninfused Limbs at Baseline and During SNP Infusion for Each Study Session

\begin{tabular}{|c|c|c|c|c|c|c|}
\hline & & & \multicolumn{3}{|c|}{ Diabetic patients } & \multirow[b]{2}{*}{ Normal subjects } \\
\hline & & & Pretreatment & Enalaprilat & 4 wk enalapril & \\
\hline \multirow[t]{4}{*}{ Infused arm } & Baseline & & $2.4 \pm 0.2$ & $2.3 \pm 0.3$ & $2.6 \pm 0.3$ & $2.5 \pm 0.4$ \\
\hline & SNP & $2 \mu \mathrm{g} / \mathrm{min}$ & $5.9 \pm 0.9$ & $5.7 \pm 0.9$ & $6.8 \pm 0.9$ & $5.9 \pm 0.9$ \\
\hline & & $4 \mu \mathrm{g} / \mathrm{min}$ & $8.6 \pm 1.5$ & $8.5 \pm 1.2$ & $8.5 \pm 1.3$ & $8.0 \pm 1.0$ \\
\hline & & $8 \mu \mathrm{g} / \mathrm{min}$ & $10.3 \pm 1.5$ & $10.1 \pm 1.4$ & $10.5 \pm 1.7$ & $10.4 \pm 1.6$ \\
\hline \multirow[t]{4}{*}{ Noninfused arm } & Baseline & & $2.8 \pm 0.4$ & $2.5 \pm 0.4$ & $2.4 \pm 0.2$ & $3.5 \pm 0.7$ \\
\hline & SNP & $2 \mu \mathrm{g} / \mathrm{min}$ & $2.9 \pm 0.5$ & $2.5 \pm 0.4$ & $2.5 \pm 0.2$ & $3.6 \pm 0.9$ \\
\hline & & $4 \mu \mathrm{g} / \mathrm{min}$ & $3.1 \pm 0.5$ & $2.8 \pm 0.6$ & $2.3 \pm 0.2$ & $3.7 \pm 1.0$ \\
\hline & & $8 \mu \mathrm{g} / \mathrm{min}$ & $3.0 \pm 0.6$ & $2.8 \pm 0.6$ & $2.3 \pm 0.2$ & $3.6 \pm 0.9$ \\
\hline
\end{tabular}

Values are means $\pm \mathrm{SE}(\mathrm{ml} / 100 \mathrm{ml}$ forearm $/ \mathrm{min})$. No significant differences existed between diabetic and normal subjects, or between treatments in diabetics. 
Table IV. Percent Changes from Baseline in the FBF Ratio Induced by Drug Infusions in Diabetic Patients; The Effects of Enalaprilat and Enalapril

\begin{tabular}{lrrrr}
\hline & & Pretreatment & Enalaprilat & 4 wk enalapril \\
\hline \multirow{2}{*}{ ACh } & $10 \mu \mathrm{g} / \mathrm{min}$ & $43 \pm 13$ & $128 \pm 35$ & $142 \pm 29$ \\
& $20 \mu \mathrm{g} / \mathrm{min}$ & $99 \pm 23$ & $173 \pm 39$ & $214 \pm 28$ \\
& $40 \mu \mathrm{g} / \mathrm{min}$ & $136 \pm 31$ & $214 \pm 37$ & $354 \pm 65$ \\
$\mathrm{SNP}$ & $2 \mu \mathrm{g} / \mathrm{min}$ & $138 \pm 19$ & $141 \pm 20$ & $144 \pm 20$ \\
& $4 \mu \mathrm{g} / \mathrm{min}$ & $254 \pm 53$ & $251 \pm 52$ & $233 \pm 37$ \\
& $8 \mu \mathrm{g} / \mathrm{min}$ & $351 \pm 65$ & $330 \pm 65$ & $315 \pm 51$ \\
& & & & \\
\hline
\end{tabular}

Values are means \pm SE. ANOVA with repeated measures indicated a significant augmentation of the response to ACh by enalaprilat $(P<$ $0.005)$ and by enalapril $(P<0.001)$ relative to pretreatment and by enalapril relative to enalaprilat $(P<0.05)$.

There were no significant differences between the diabetic and normal subjects' responses to SNP in terms of absolute FBF (Table III), FBF ratio, or vascular resistance (data not shown). In addition, there was no effect of acute or short-term ACE inhibition on SNP responses in the diabetic group (Table IV, Fig. 1).

\section{Discussion}

The most important findings of this study are that endothelial function, as assessed by endothelium-dependent vasodilation to ACh which is mediated mainly through NO, was improved substantially after only 4 wk of therapy with the ACE inhibitor enalapril in type I diabetic patients; secondly a significant improvement, although of smaller magnitude, was seen with intraarterial enalaprilat, the active form of enalapril. The latter indicates an acute effect of ACE inhibition and probably a local effect, although it is possible that the enalaprilat had an un-

Table V. Resistance in the Infused Limb During ACh and SNP Infusions for Each Study Session; The Effects of Enalaprilat and Enalapril

\begin{tabular}{lcccr}
\hline & & Pretreatment & Enalaprilat & 4 wk enalapril \\
\hline Baseline & & $45.7 \pm 4.4$ & $49.5 \pm 7.0$ & $41.2 \pm 7.0$ \\
ACh & $10 \mu \mathrm{g} / \mathrm{min}$ & $32.4 \pm 3.6$ & $24.2 \pm 3.0$ & $19.1 \pm 2.5$ \\
& $20 \mu \mathrm{g} / \mathrm{min}$ & $23.5 \pm 2.6$ & $19.7 \pm 1.9$ & $13.7 \pm 1.5$ \\
& $40 \mu \mathrm{g} / \mathrm{min}$ & $19.0 \pm 1.9$ & $18.0 \pm 2.2$ & $10.3 \pm 1.2$ \\
Baseline & & $41.6 \pm 4.4$ & $46.3 \pm 6.6$ & $37.6 \pm 5.4$ \\
SNP & $2 \mu \mathrm{g} / \mathrm{min}$ & $18.3 \pm 2.3$ & $19.4 \pm 3.3$ & $15.3 \pm 2.5$ \\
& $4 \mu \mathrm{g} / \mathrm{min}$ & $12.8 \pm 1.8$ & $13.1 \pm 2.3$ & $12.6 \pm 2.1$ \\
& $8 \mu \mathrm{g} / \mathrm{min}$ & $10.4 \pm 1.4$ & $11.1 \pm 2.2$ & $9.8 \pm 1.6$ \\
& & & & \\
\hline
\end{tabular}

Values are means $\pm \mathrm{SE}(\mathrm{mmHg}$ per $\mathrm{ml} / 100 \mathrm{ml}$ tissue/min).) ANOVA with repeated measures indicated a significant augmentation of the response to ACh by enalaprilat $(P<0.005)$ and by enalapril $(P<0.001)$ relative to pretreatment and by enalapril relative to enalaprilat $(P<$ $0.05)$.

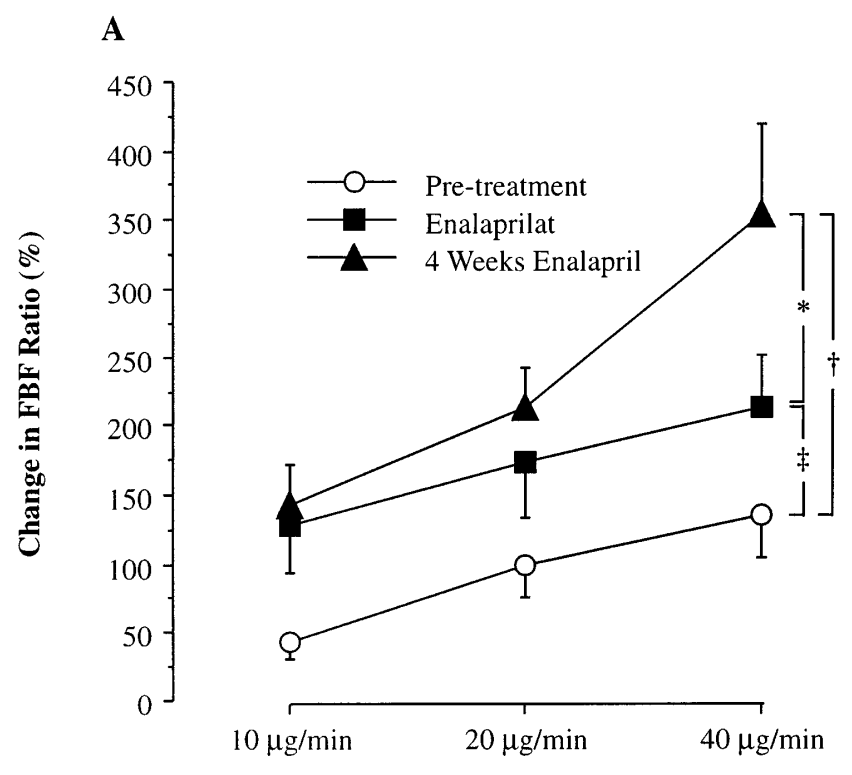

B

Acetylcholine

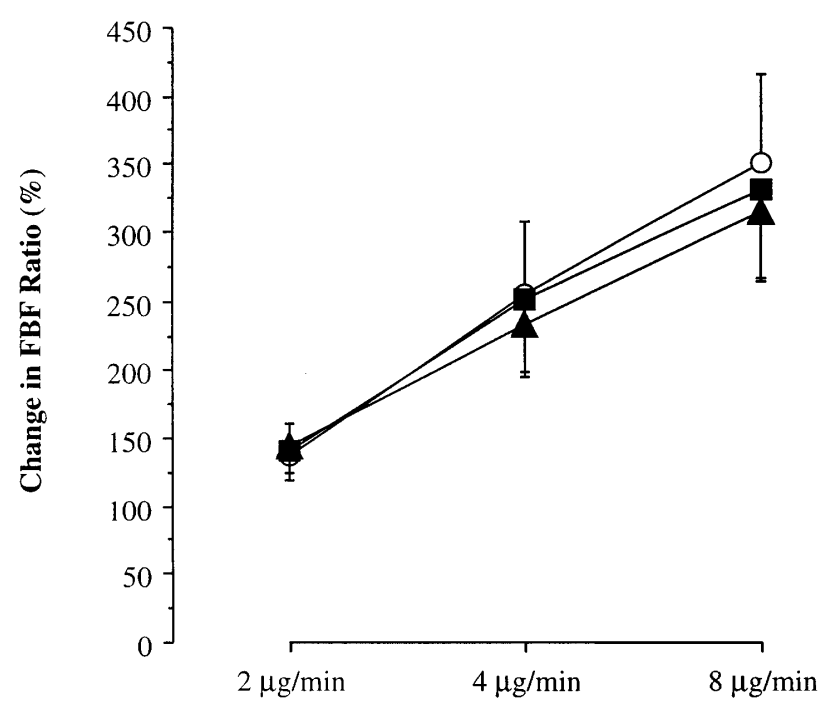

Sodium Nitroprusside

Figure 1. The effects of enalaprilat and enalapril on FBF ratios in diabetic patients, for three dose levels of $\mathrm{ACh}(A)$ and SNP $(B)$, are illustrated. Results are expressed as means \pm SE. ${ }^{*} P=0.05,{ }^{\ddagger} P<0.001$, ${ }^{\dagger} P<0.005$, ANOVA.

detected systemic effect. Others have found an acute effect of ACE inhibition; intraarterial enalaprilat improves endothelium-dependent vasodilatation in heart failure patients (13) and intravenous administration of perindoprilat acutely improved the endothelium-dependent coronary dilator response to papaverine-induced increase in coronary flow in hypertensive patients (23).

In our study, the effects of both enalaprilat and enalapril were most apparent when the data obtained in the infused arm were referenced to the noninfused arm, the rationale for which has been reviewed recently (21), although the responses were evident in absolute forearm flow and vascular resistance 
changes. After 4 wk, enalapril therapy was associated with a small hypotensive effect, but no significant hypotension resulted from the local administration of enalaprilat and neither drug was associated with a change in basal FBF. This suggests that a hypotensive effect per se was not responsible for improving endothelial function and, more conclusively, the response to the endothelium-dependent stimulant ACh was improved while the response to the endothelium-independent vasodilator SNP was not. Other evidence that the effect of ACE inhibition on endothelial function is not closely dependent upon blood pressure lowering was well summarized in the recent study on perindoprilat quoted above (23). For example, Hirooka et al. (14) found that captopril improved endothelial function while nifedipine, in equipotent hypotensive doses, did not. We are, of course, not suggesting that the improvement in endothelial function with ACE inhibition is specific to type I diabetic subjects, but the improvement in type I diabetics is likely to be of considerable clinical importance and, as discussed below, may be related to the actions of insulin and to abnormal metabolism in diabetes.

The vasodilator response of the diabetic patients to ACh was depressed relative to that of normal subjects recruited in a recent study (20). These normal subjects were younger than the diabetic subjects, their ages averaging 28 and $43 \mathrm{yr}$, respectively. Although there is an apparent age-related decline in endothelial function (24), the decline does not commence until $\sim 40 \mathrm{yr}$ of age, is small, and is unlikely to explain the depressed endothelial function in the diabetic patients. The interpretation that endothelium-dependent vasodilatation is defective in type I diabetics accords with the majority of findings; Johnstone et al. (11) found depressed forearm resistance vessel responses to methacholine and preserved responses to SNP in type I diabetics while results with competitive antagonists of NO synthesis have implied decreased basal NO-mediated dilatation $(9,10)$. Conversely, other studies have not detected abnormality in NO-dilator system activity $(25,26)$. Some of the variability could reflect differences in patient characteristics. For example, while the basal NO-dilator effect was clearly depressed in type I diabetic subjects with albuminuria, compared to normals, it was intermediate and equivocal in those without albuminuria (10). However, our patients did not have albuminuria, other manifestations of diabetic vascular disease, nor hyperlipidemia or hypertension, known to be associated with endothelial dysfunction. Depressed endothelial function has been demonstrated convincingly in the forearm resistance bed of type II diabetics $(27,28)$ and in epicardial coronary conduit vessels of both type I and type II diabetics $(5,29)$. The mechanisms responsible are unclear. As discussed recently (28), the defect in the system in diabetes might be due to diminished production of $\mathrm{NO}$ or more likely to increased quenching of $\mathrm{NO}$ by advanced glycosylation products associated with diabetes $(8,30)$ or oxygen-derived free radicals $(31-33)$. The mechanisms might differ between type I and type II diabetes since studies in type II diabetes, demonstrating depressed endothelium-dependent responses, have also found depressed responsiveness to glyceryl trinitrate (27) and SNP (28).

The results of this study, performed in a vascular bed not prone to gross atherosclerosis, strongly suggest that there is general improvement in endothelial function as a result of ACE inhibition in type I diabetics, at least in males without albuminuria or symptomatic vascular complications. The latter constituted exclusions from our study and females were not in- cluded because of the likely effects of hormonal variation. There is no previous evidence of a beneficial effect of ACE inhibitors on endothelial function in diabetic subjects. One study, which examined the effect of a substantial dose of perindopril for 6 mo in type II diabetics, failed to find an improvement in the forearm response to methacholine although postischemic hyperemia was increased (17). These patients, being type II diabetics, were older and also mildly obese, hypertensive, and hypercholesterolemic, all of which might have combined to mitigate against improvement. Type I diabetic subjects were excluded from the recent study which reported an augmented response to $\mathrm{ACh}$ in both large epicardial arteries and in coronary resistance vessels after 6 mo of therapy with quinapril (16).

A number of potential explanations exist for the influence of ACE inhibition on endothelial function and these have been reviewed recently by Rajagopalan and Harrison (34). Other evidence indicates a probable relation with insulin metabolism; administration of ACE inhibitors has been reported to potentiate the hypoglycemic effect of insulin (35) and to improve glycemic control (36). Studies indicate that coinfusion of insulin increases the forearm vasodilator response to ACh (37) and that the forearm vasodilator response to systemically administered insulin is reduced by inhibiting NO synthesis with L-NMMA (35). Further, in normal subjects the forearm constrictor response to inhibition of NO synthesis has been reported to correlate inversely with the degree of insulin resistance assessed by the euglycemic hyperinsulinemic clamp technique (38); that is, resistance to the cellular action of insulin seems to be associated with a lower basal NO-dilator effect. These findings together indicate that insulin acts to augment the NO-dilator system, either through increasing NO production, increasing its effectiveness, or both.

ACE inhibition might improve endothelial NO-mediated dilator function either through suppression of angiotensin II production, inhibition of bradykinin breakdown, or through other mechanisms (34). For example, angiotensin II has been found to increase the activity of vascular NADH oxidase in the rat and, probably related to this, the vascular production of superoxide anions, while selective blockade of angiotensin type I receptors reduced superoxide production (39). These studies extend previous observations of antioxidant effects of ACE inhibitor drugs (40-43) and suggest that suppression of superoxide production is likely to be particularly relevant in the diabetic state (31-33). Additionally, decreased production of angiotensin II could act through protein kinase $\mathrm{C}$ and consequent increase in NO synthase activity, leading to increased NO synthesis (34). Alternatively, the effect of ACE inhibition could be mediated through the actions of bradykinin; ACE inhibitors not only inhibit the conversion of angiotensin I to angiotensin II, but also the degradation of bradykinin by bradykininase II since this enzyme and ACE are identical. Bradykinin stimulates NO production by endothelial cells, so that preservation of bradykinin, via enzyme inhibition, would be expected to augment NO dilator system activity $(44,45)$. Finally, other mediators such as the prostaglandins (12) may be involved in the response to ACE inhibitors under some circumstances. ACE inhibition may also be relevant to the atherosclerotic process in the longer term via reduction in cytokine activation and leukocytic migration into the vascular wall (46), reduced oxidation of LDL cholesterol (47), or reduction of neointimal proliferation (48). 
In summary, we have shown that 4 wk of enalapril therapy considerably augments the endothelium-dependent response to ACh stimulation, which is largely dependent upon the integrity of the NO-dilator system, in type I diabetic subjects. It remains to be seen whether this improvement in basic vascular function is translated into a reduction in vascular mortality and morbidity.

\section{Acknowledgments}

We are grateful to Merck, Sharpe and Dohme (Australia) for the supply of enalaprilat and enalapril.

This study was supported by Healthway, Western Australia, and the Royal Perth Hospital Medical Research Foundation.

\section{References}

1. Chowienczyk, P.J., G.F. Watts, J.R. Cockcroft, and J.M. Ritter. 1992. Impaired endothelium-dependent vasodilation of forearm resistance vessels in hypercholesterolaemia. Lancet. 340:1430-1432.

2. Calver, A., J. Collier, S. Moncada, and P. Vallance. 1992. Effect of intraarterial $N^{\mathrm{G}}$-monomethyl-L-arginine in patients with hypertension: the nitric oxide dilator system appears impaired. J. Hypertens. 10:1025-1031.

3. Celermajer, D.S., K.E. Sorensen, D. Georgakopoulos, C. Bull, O. Thomas, J. Robinson, and J.E. Deanfield. 1993. Cigarette smoking is associated with dose-related and potentially reversible impairment of endothelium-dependent dilation in healthy young adults. Circulation. 88:2149-2155.

4. Celermajer, D.S., M.R. Adams, P. Clarkson, J. Robinson, R. McCredie, A. Donald, and J.E. Deanfield. 1996. Passive smoking and impaired endothelium-dependent arterial dilatation in healthy young adults. N. Engl. J. Med. 334: $150-154$

5. Reddy, K.G., R. Nair, H.M. Sheehan, and J.M. Hodgson. 1994. Evidence that selective endothelial dysfunction may occur in the absence of angiographic or ultrasound atherosclerosis in patients with risk factors for atherosclerosis. $J$. Am. Coll. Cardiol. 23:833-843.

6. Celermajer, D.S., K.E. Sorensen, C. Bull, J. Robinson, and J.E. Deanfield. 1994. Endothelium-dependent dilation in the systemic arteries of asymptomatic subjects relates to coronary risk factors and their interaction. J. Am. Coll. Cardiol. 24:1468-1474.

7. Tesfamariam, B., M.L. Brown, D. Deykin, and R.A. Cohen. 1990. Elevated glucose promotes generation of endothelium-derived vasoconstrictor prostanoids in rabbit aorta. J. Clin. Invest. 85:929-932.

8. Bucala, R., K.J. Tracey, and A. Cerami. 1991. Advanced glycosylation products quench nitric oxide and mediate defective endothelium-dependent vasodilatation in experimental diabetes. J. Clin. Invest. 87:432-438.

9. Calver, A., J. Collier, and P. Vallance. 1992. Inhibition and stimulation of nitric oxide synthesis in the human forearm arterial bed of patients with insulindependent diabetes. J. Clin. Invest. 90:2548-2554.

10. Elliott, T.G., J.R. Cockcroft, P.H. Groop, G.C. Viberti, and J.M. Ritter. 1993. Inhibition of nitric oxide synthesis in forearm vasculature of insulindependent diabetic patients: blunted vasoconstriction in patients with microalbuminuria. Clin. Sci. (Lond.). 85:687-693.

11. Johnstone, M.T., S.J. Creager, K.M. Scales, J.A. Cusco, B.K. Lee, and M.A. Creager. 1993. Impaired endothelium-dependent vasodilation in patients with insulin-dependent diabetes mellitus. Circulation. 88:2510-2516.

12. Drexler, H., S. Kurz, M. Jeserich, T. Munzel, and B. Hornig. 1995. Effect of chronic angiotensin-converting enzyme inhibition on endothelial function in patients with chronic heart failure. Am. J. Cardiol. 76:13E-18E.

13. Nakamura, M., T. Funakoshi, N. Arakawa, H. Yoshida, S. Makita, and K. Hiramori. 1994. Effect of angiotensin-converting enzyme inhibitors on endothelium-dependent peripheral vasodilation in patients with chronic heart failure. J. Am. Coll. Cardiol. 24:1321-1327.

14. Hirooka, Y., T. Imaizumi, H. Masaki, S. Ando, S. Harada, M. Momohara, and A. Takeshita. 1992. Captopril improves impaired endothelium-dependent vasodilation in hypertensive patients. Hypertension. 20:175-180.

15. Nakamura, M., T. Funakoshi, H. Yoshida, N. Arakawa, T. Suzuki, and K. Hiramori. 1992. Endothelium-dependent vasodilation is augmented by angiotensin converting enzyme inhibitors in healthy volunteers. J. Cardiovasc. Pharmacol. 20:949-954.

16. Mancini, G.B., G.C.H. Henry, C. Macaya, B.J. O’Neill, A.L. Pucillo, R.G. Carere, T.J. Wargovich, H. Mudra, T.F. Lüscher, M.I. Klibaner, et al. 1996. Angiotensin converting enzyme inhibition, with quinapril, improves endothelial vasomotor dysfunction in patients with coronary artery disease: The TREND Study (Trial on Reversing Endothelial Dysfunction). Circulation. 94: 258-265.

17. Bijlstra, P.J., P. Smits, J.A. Lutterman, and T. Thien. 1995. Effect of long-term angiotensin-converting enzyme inhibition on endothelial function in patients with the insulin-resistance syndrome. J. Cardiovasc. Pharmacol. 25: 658-664.

18. Viberti, G., C.E. Mogensen, L.C. Groop, and J.F. Pauls. 1994. Effect of captopril on progression to clinical proteinuria in patients with insulin-dependent diabetes mellitus and microalbuminuria. J. Am. Med. Assoc. 271:275-279.

19. Laffel, L.M.B., J.B. McGill, and D.J. Gans. 1995. The beneficial effect of angiotensin-converting enzyme inhibition with captopril on diabetic nephropathy in normotensive IDDM patients with microalbuminuria. Am. J. Med. 99: 497-504.

20. Green, D.J., D.T. Fowler, J.G. O'Driscoll, B.A. Blanksby, and R. Taylor. 1996. Endothelium-derived nitric oxide activity in forearm vessels of tennis players. J. Appl. Physiol. 81:943-948.

21. Benjamin, N., A. Calver, J. Collier, B. Robinson, P. Vallance, and D. Webb. 1995. Measuring forearm blood flow and interpreting the responses to drugs and mediators. Hypertension. 25:918-913.

22. Green, D.J., J.G. O'Driscoll, B.A. Blanksby, and R.R. Taylor. 1995. Lack of effect of vitamin E administration on basal nitric oxide function in male smokers and non-smokers. Clin. Sci. 89:343-348.

23. Antony, I., G. Lerebours, and A. Nitenberg. 1996. Angiotensin-converting enzyme inhibition restores flow-dependent and cold pressor test-induced dilations in coronary arteries of hypertensive patients. Circulation. 94:3115-3122.

24. Celermajer, D.S., K.E. Sorensen, D.J. Spiegelhalter, D. Georgakopoulos, J. Robinson, and J.E. Deanfield. 1994. Aging is associated with endothelial dysfunction in healthy men years before the age-related decline in women. $J$. Am. Coll. Cardiol. 24:471-476.

25. Smits, P., J.A. Kapma, M.C. Jacobs, J. Lutterman, and T. Thien. 1993. Endothelium-dependent vascular relaxation in patients with type I diabetes. Diabetes. 42:148-153.

26. Halkin, A., N. Benjamin, H.S. Doktor, S.D. Todd, G. Viberti, and J.M. Ritter. 1991. Vascular responsiveness and cation exchange in insulin-dependent diabetes. Clin. Sci. (Lond.). 81:223-232.

27. McVeigh, G.E., G.M. Brennan, G.D. Johnston, B.J. McDermott, L.T. McGrath, W.R. Henry, J.W. Andrews, and J.R. Hayes. 1992. Impaired endothelium-dependent and independent vasodilation in patients with type 2 (noninsulin-dependent) diabetes mellitus. Diabetologia. 35:771-776.

28. Williams, S.B., J.A. Cusco, M.A. Roddy, M.T. Johnstone, and M.A Creager. 1996. Impaired nitric oxide-mediated vasodilation in patients with non-insulin-dependent diabetes mellitus. J. Am. Coll. Cardiol. 27:567-574.

29. Nitenberg, A., P. Valensi, R. Sachs, M. Dali, E. Aptecar, and J.R. Attali. 1993. Impairment of coronary vascular reserve and ACh-induced coronary vasodilation in diabetic patients with angiographically normal coronary arteries and normal left ventricular systolic function. Diabetes. 42:1017-1025.

30. Brownlee, M., A. Cerami, and H. Vlassara. 1988. Advanced glycosylation end products in tissue and the biochemical basis of diabetic complications. N. Engl. J. Med. 318:1315-1321.

31. Kawamura, M., J.W. Heinecke, and A. Chait. 1994. Pathophysiological concentrations of glucose promote oxidative modification of low density lipoprotein by a superoxide-dependent pathway. J. Clin. Invest. 94:771-778.

32. Baynes, J.W. 1991. Role of oxidative stress in development of complications in diabetes. Diabetes. 40:405-412.

33. Ting, H.H., F.K. Timimi, K.S. Boles, S.J. Creager, P. Ganz, and M.A Creager. 1996. Vitamin C improves endothelium-dependent vasodilation in patients with non-insulin-dependent diabetes mellitus. J. Clin. Invest. 97:22-28.

34. Rajagopalan, S., and D.G. Harrison. 1996. Reversing endothelial dysfunction with ACE inhibitors. A new TREND? Circulation. 94:240-243.

35. Scherrer, U., D. Randin, P. Vollenweider, L. Vollenweider, and P. Nicod. 1994. Nitric oxide release accounts for insulin's vascular effects in humans. J. Clin. Invest. 94:2511-2515.

36. Torlone, E., M. Britta, A.M. Rambotti, G. Perriello, F. Santeusanio, P. Brunetti, and G.B. Bolli. 1993. Improved insulin action and glycemic control after long-term angiotensin-converting enzyme inhibition in subjects with arterial hypertension and type II diabetes. Diabetes Care. 16:1347-1355.

37. Taddei, S., A. Viridis, P. Mattei, A. Natali, E. Ferrannini, and A. Salvetti. 1995. Effect of insulin on acetylcholine-induced vasodilation in normotensive subjects and patients with essential hypertension. Circulation. 92:29112918.

38. Petrie, J.R., S. Ueda, D.J. Webb, H.L. Elliott, and J.M.C. Connell. 1996 Endothelial nitric oxide production and insulin sensitivity. A physiological link with implications for pathogenesis of cardiovascular disease. Circulation. 93: 1331-1333.

39. Rajagopalan, S., S. Kurz, T. Münzel, M. Tarpey, B. Freeman, K. Griendling, and D. Harrison. 1996. Angiotensin II mediated hypertension in the rat in creases vascular superoxide production via membrane NADH/NADPH oxidase activation: contribution to alterations of vasomotor tone. J. Clin. Invest. 97:1916-1923.

40. Andreoli, S.P. 1993. Captopril scavenges hydrogen peroxide and reduces, but does not eliminate, oxidant-induced cell injury. Am. J. Physiol. 264: F120-F127.

41. Haklar, G., C. Ersahin, H. Moini, M. Sungun, N. Dogan, S. Bilsel, K. Emerk, and A.S. Yalcin. 1995. Protective effects of cilazapril against free radical injury in myocardial ischaemia-reperfusion. Pharmacol. Res. 31:33-36.

42. Kaufman, M.J. 1994. Comparison of the free radical-scavenging ability 
of captopril and ascorbic acid in an in-vitro model of lipid oxidation. Implications for reperfusion injury and ACE inhibitor therapy. J. Pharm. Pharmacol. 46:217-220.

43. Mira, M.L., M.M. Silva, M.J. Queiroz, and C.F. Manso. 1993. Angiotensin converting enzyme inhibitors as oxygen free radical scavengers. Free Radic. Res. Commun. 19:173-181.

44. Vanhoutte, P.M., C.M. Boulanger, and J.V. Mombouli. 1995. Endothelium-derived relaxing factors and converting-enzyme inhibition. Am. J. Cardiol. 76:3E-12E.

45. Auch-Schwelk, W., E. Duske, M. Claus, K. Graf, M. Gräfe, and E. Fleck. 1995. Endothelium-mediated vasodilation during ACE inhibition. Eur.
Heart J. 16(Suppl. C):59-65.

46. Clapperton, M., J. McMurray, A.C. Fisher, and H.J. Dargie. 1994. The effect of angiotensin-converting enzyme inhibitors on human neutrophil chemotaxis in vitro. Br. J. Clin. Pharmacol. 38:53-56.

47. Fennessy, P.A., J.H. Campbell, and G.R. Campbell. 1994. Perindopril inhibits both the development of atherosclerosis in the cholesterol-fed rabbit and lipoprotein binding to smooth muscle cells in culture. Atherosclerosis. 106 : $29-41$.

48. Farhy, R.D., K.L. Ho, O.A. Carretero, and A.G. Scicli. 1992. Kinins mediate the antiproliferative effect of ramipril in rat carotid artery. Biochem. Biophys. Res. Commun. 182:283-288. 